such as genetic sequencing, have become cheaper and lab work has become automated. The cost of starting biotech companies is falling, lowering the risk for investors to fund new science-based companies. IndieBio and Y Combinator - an information-technology incubator in Mountain View, California, that started accepting biotech companies in 2014 - provide funding and mentoring to entrepreneurs in exchange for shares in the companies.

\section{FORK IN THE ROAD}

Y Combinator, which provides US $\$ 120,000$ in seed funding per company, invested in Perlara this year; IndieBio, which provides $\$ 250,000$ per start-up, has funded 42 companies in a variety of fields. Last year, biotech firms in the United States and Europe raised $\$ 3.5$ billion in early-stage financing - more than in any previous year, according to the consultancy Ernst \& Young. Much of this was from investors who have already made money in technology.

"Most of the venture guys I know want to change the world for the better," says Dan Widmaier, co-founder and chief executive of Bolt Threads in Emeryville, California, which uses genetic engineering to manufacture textiles. Widmaier went to work for the company three days after completing his $\mathrm{PhD}$ in 2010. "As they see it, being able to serve up an ad faster probably isn't changing the world for the better as much as being able to solve climate change or cure disease."

Conventional academic paths are also becoming less appeal"Most of the venture guys I know want to change the world for the better." ing. On average, young scientists earn their first US National Institutes of Health R01 grant - the bread-and-butter support for most biomedical scientists - at the age of 42. When Anitha Jayaprakash earned her genetics PhD from the Icahn School of Medicine at Mount Sinai in New York City in 2014, she saw scientists all around her stuck in postdocs. Many had no hope of finding their own tenure-track academic jobs - a phenomenon that Perlstein has dubbed the "postdocalypse". "It gave me a very depressing feeling about the whole academic space," says Jayaprakash. So she started Girihlet, a genetic-sequencing company in Berkeley, California, that has received funding from IndieBio and other investors.

Alexander Lorestani felt the same way when he left a joint graduate and medicaldegree programme in 2015 to co-found Geltor in San Leandro, California, which makes a vegan alternative to animal gelatin. He and his co-founder are 29 and 30 years old, and felt ready to use science to serve humanity. "I couldn't imagine waiting another five to ten years to dive into doing what I think of as my life's work," Lorestani says.

It's not an easy road. Most young biotech firms fail. Widmaier says that he never expected Bolt Threads to raise $\$ 90$ million and last for 6 years. He says it has been rewarding to thrive long enough to be doing groundbreaking science - and to have a rare degree of independence. "Anywhere else, you join someone else's vision for what a perfect workplace is," he says. "The most valuable thing about building a company is that you get to build the place where you go to work every day." -

\title{
HELIOPHYSICS
}

\section{Hiccups for US satellite}

\section{Cosmic rays may be inducing glitches in space-weather probe's computer.}

\section{BY ALEXANDRA WITZE}

A space-weather satellite that is supposed to alert Earth to incoming solar storms has temporarily dropped offline six times in the year since it became operational. The US craft's onboard computer may be experiencing hiccups caused unexpectedly by Galactic cosmic rays.

The Deep Space Climate Observatory (DSCOVR) went out of action most recently on 30 October. In each case, it unexpectedly entered a 'safe hold', in which scientific data stopped flowing and engineers had to scramble to try to recover the spacecraft. In total, DSCOVR's space-weather forecasting instruments have been offline for more than 42 hours since 28 October 2015, when the US National Oceanic and Atmospheric Administration (NOAA) took the spacecraft over from NASA, which built and launched it.

Each outage lasts for only a few hours, and the total downtime amounts to more than $0.5 \%$ of its time in space - well within NOAA's requirement that the spacecraft operate at least $96 \%$ of the time. The 11 October outage did not significantly affect predictions of a minor geomagnetic storm that arrived a

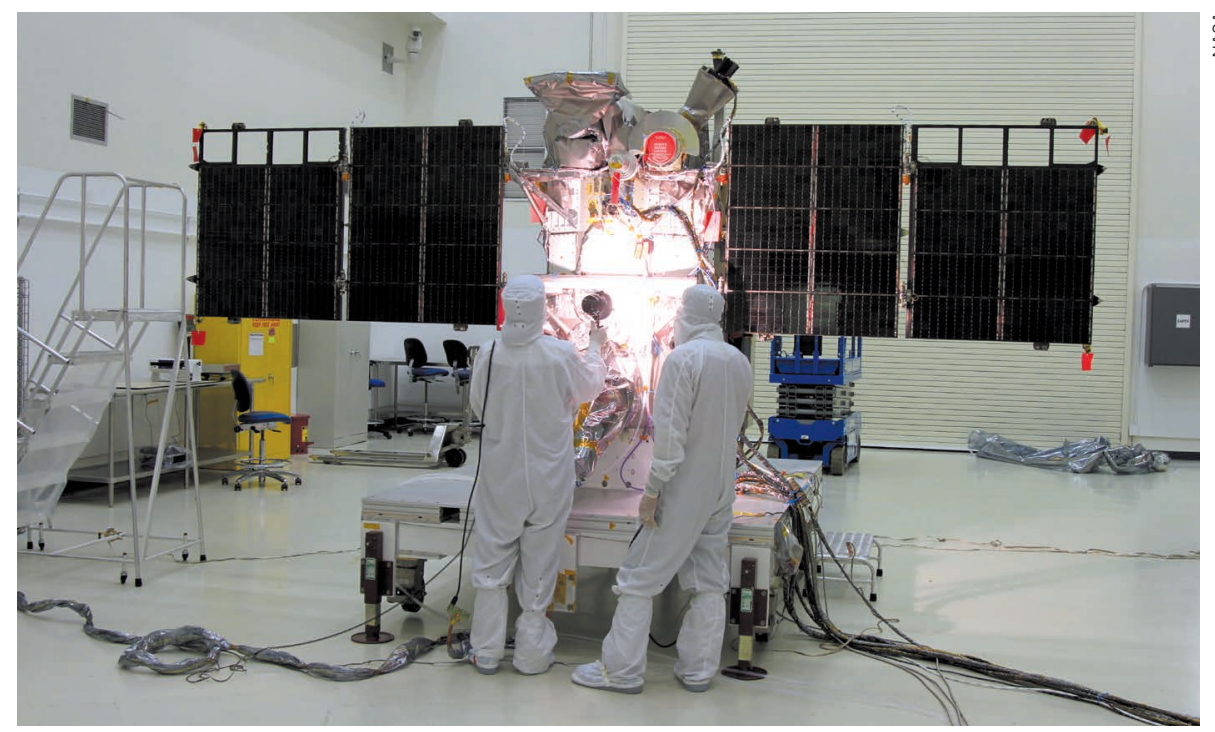

Workers test solar arrays on the DSCOVR satellite, which is now used to monitor space weather.

few days later, says Robert Rutledge, head of the forecast office at NOAA's Space Weather Prediction Center in Boulder, Colorado.

But the outages mean that DSCOVR could be offline when a major solar storm erupts, leaving Earth essentially blind to the incoming onslaught. "Are they problematic? Yes," says Douglas Biesecker, a solar physicist at the Boulder centre.

Other heliophysics spacecraft monitor solar eruptions, but DSCOVR delivers unique information from its location at 
